\title{
A Simulation Method for the Optimization of Cooling Water Slot Structure in Slab Continuous Casting Mold Combined With SEN
}

\author{
Sang Chol Om ( $\square$ osc80410@star-co.net.kp ) \\ Kim Chaek University of Technology \\ Dong-Gil Kim \\ Kim Chaek University of Technology \\ Chong-II Pak \\ Kim Chaek University of Technology \\ Hak-Yong Kim \\ Kim Chaek University of Technology \\ II-Un Kim \\ Kim Chaek University of Technology
}

\section{Research Article}

Keywords: Continuous casting, Mold, Cooling water slots, Heat flux density

Posted Date: October 19th, 2021

DOl: https://doi.org/10.21203/rs.3.rs-906051/v1

License: (c) (i) This work is licensed under a Creative Commons Attribution 4.0 International License. Read Full License 


\title{
A simulation method for the optimization of cooling water slot structure in slab continuous casting mold combined with SEN
}

\author{
Sang Chol Om*, Dong Gil Kim, Chong Il Pak, Hak Yong Kim, Il Un Kim \\ Faculty of Materials Science and Technology, Kim Chaek University of Technology, 60 Kyogu, \\ Pyongyang, Democratic People's Republic of Korea
}

\begin{abstract}
The temperature field in the full 3D finite element mold model combined with submerged entry nozzle(SEN)(Full SEN-3D FEMM) is simulated with Fluent of ANSYS 18.0 Package to apply the maximum heat flux density on the heat face of mold copper plate obtained through this simulation to the element model of the copper plate, and thermal stress and strain simulations on the copper plate and stainless back ones are conducted with Workbench of ANSYS 18.0 Package to confirm the reasonable designing factors for the water slot structure on the copper plate. The maximum heat flux densities on the wide and narrow heat faces of the copper plates are given on the initial shock areas of molten steel flux injected through SEN. With constant heat flux density on the heat face, the more the thickness of copper plate increases, the more the max- and min temperatures increase and the difference between them decreases. Elastic and plastic deformations on the copper plate are made during continuous casting $(\mathrm{CC})$ process; the former occurs around the water slots and the latter around the heat face with the highest temperature, which regards 20-18-17 as the most reasonable one among 4 plans for the water slot structure.
\end{abstract}

Keywords: Continuous casting, Mold, Cooling water slots, Heat flux density

\section{Corresponding author: Sang Chol Om}

Institute: Faculty of Materials Science and Technology, Kim Chaek University of Technology, 60 Kyogu, Pyongyang, Democratic People's Republic of Korea

E-mail: osc80410@star-conet.kp(S.C.Om). 


\section{Introduction}

Mold plays a very important role in the total cooling process of slab in the mold as the first cooling stage where molten steel is solidified. Thus, the mold is called the "heart" of a continuous caster [1,2]. During the CC process, the molten steel is continuously poured into the water-cooled mold through SEN, which forms a solidified shell of sufficient thickness when the slab is pulled out. The slab quality, particularly regarding surface and internal cracks, is closely related to the turbulent flow in the mold and the heat transfer through the heat face on the mold copper plate during the solidification in a $\mathrm{CC}$ process [3]. A large temperature gradient is formed on the total section of copper plate during CC process, which generates strain and thermal stress in the copper plate. In case the thermal stress occurred by the temperature gradient in the mold copper plate is excessive, strain occurs in the mold copper plate, and with increase of casting time and constant iteration of heating and cooling process on the copper plate, micro cracks are generated and extended to make an irretrievable accident in the copper plate [4].

Nowadays many studies on the temperature and thermal stress fields in the mold copper plate have been progressed. Meng Xiangning and Zhu MiaoYong [5] established a 3-dimensional finite element model to simulate temperature field of the heat face on the mold copper plate and predicted the effect of casting speed on the temperature field distribution on the heat face of the mold. Xin Xie and his co-workers [6] established 3-dimensional heat transfer model combined with flow character of the cooling water to analyze the temperature field of the copper plate and water slots by comparing with Dittus-Boelter and Selicher-Rouse models.

Wang Xudong [7], Ren Feifei [8] predicted the temperature field and heat flux density by using numeric simulation method based on an inverse finite element (FE) model.

Badri A and his co-workers [9] designed a mold simulator and progressed a basic experiment on the heat transfer, the formation of solidified shell and oscillation mark during the $\mathrm{CC}$ process of low-carbon steel, and demonstrated that the maximum heat flux density around the meniscus changes in the range of $2.4 \sim 2.8 \mathrm{MW} / \mathrm{m}^{2}$ with the oscillating period of mold.

Fegming Dua et al [10] established 2-dimensional full finite-element model and analyzed the 2-dimensional temperature field on the mold copper plate considered nickel coating layer in the curved continuous caster. Zhao-zhen Cai et al [11, 12] simulated 2-dimensional numerical 
value on the slab mold taper considered shrinkage of peritectic steel during the CC process and predicted the distribution of the thickness of both mold flux and air gap along the height direction of mold.

David T Stone and Brain G. Thomas [13] manufactured a simple experimental apparatus and calculated numerically the temperature gradient, thermal conduction and thermal contact resistance values on the section of the steel plate-mold flux gap-mold copper plate in the 2 dimensional model, using the temperature values measured from thermocouples that were placed in different positions and the thermal conductivity of copper plate already known, heating the steel plate from outside and injecting mold flux into the gap between the copper and steel plates.

Wand Xudong and his co-workers [14] developed mathematical inverse heat transfer problem(IHTP) based on the temperature of mold and casting condition measured experimentally, and simulated the effects of slag film evolution, the formation of air gap and the heat transfer character to ascertain the non-equilibrium distribution of air gap and the liquid/solid slag film.

Éldarkhanov A. S. [15] demonstrated the effect of the oscillating motion and gap size between CC mold and solidified crust, and the cooling water slot structure of mold copper plate on the heat transfer into mold and derived the mathematical relational expression.

Meng Xiangning and Zhu Miaoyong [16] established a finite-element entity model of slab continuous casting mold and studied the effects of thickness of copper plates and nickel layers and depth of water slots on the temperature of heat face and cross section in the mold.

Liu Xudong, Zhu Miaoyong [4] established the 3-dimensional heat transfer and thermal stress finite element model and predicted the temperature, deformation and thermal stress in a continuous casting mold for steel slab by using a commercial finite element analysis package ANSYSTM. Zhou J his co-workers [17] established the 3-dimensional coupled thermalmechanical model of a mold-billet system regarding the total top face of the slab in the mold as the pouring hole during continuous casting, and analyzed the temperature field and stress field in mold copper plate taking into account the latent heat released during phase transformation, the heat transfer and the interaction between the moving billet and the mold.

Duan Mingnan and his co-workers [18] applied the heat flux density that calculated from the inverse model using the temperature values measured by the thermocouples inserted in the 
copper plate to the mold heat face and established 2-dimensional model that applied the heat exchange coefficient derived from the Dittus-Boelter's empirical formula on the cold surface of copper plate. Next, they analyzed stress distribution on each section of mold copper plate by using ANSYS program. W. Luo and his co-workers [19] established 2-dimensional thermal-elasticplastic-creep finite element models of beam blank molds with different water slot designs, the large hole mold and the small hole mold, and studied their thermo-mechanical character by means of ABAQUS software.

Based on these above reference data, we can draw some conclusions as follows:

In case of most of numerical simulations on temperature field in the mold copper plate, empirical formulas on already-developed heat flux density were used or applied was the value obtained by applying the temperature measured from the thermocouple inserted in the mold copper plate to the inverse finite-element model, and applied the heat exchange coefficient between the cold face on the copper plate and cooling water calculated by means of Dittus-Boelter`s formula to the boundary condition of the cold face on the copper plate.

These methods have the advantages of saving time for simulation calculating, but in case the temperature value measured from the thermocouple inserted in the mold isn 't precise enough, it is felt difficult to ensure the accuracy of simulation result and especially to reflect the effect of many factors as it was when using empirical formulas. To get the thing worse, there are hardly thought to exist data where the temperature field in the mold copper plate is analyzed by using the 1/4 model of Full SEN-3D FEMM while considering heat flux into the mold copper plate from molten steel in turbulent flow state, of course together with the thermal contact resistance such as mold flux, gap and coating layer.

In this paper, simulated is the temperature field in a Full SEN-3D FEMM considered the flux character of molten steel through SEN, mold flux and coating layer, and stainless back plate in the mold, and also simulated is the temperature field and heat stress and strain on mold copper and stainless back plates by applying the maximum heat flux density on the heat face of copper plate in the model obtained from the above simulation to the element model of the mold copper plate, thereby confirming the reasonable designing factors for the water slot structure on the mold copper plate through this process. 


\section{FE modeling}

\subsection{Geometrical shape of the mold}

\subsubsection{1/4 model of Full SEN-3D FEMM}

The geometric model based on the real dimension of the mold that is used in a continuous casting process is shown in Fig. 1. Only 1/4 one of the real model is designed for simulation to reduce the computation cost. To demonstrate the effect of the turbulent flow character of the injected molten steel in the mold on the heat transfer process with the mold copper plate, the molten steel flow was poured by means of SEN. The stainless back plates are set behind the mold copper ones.

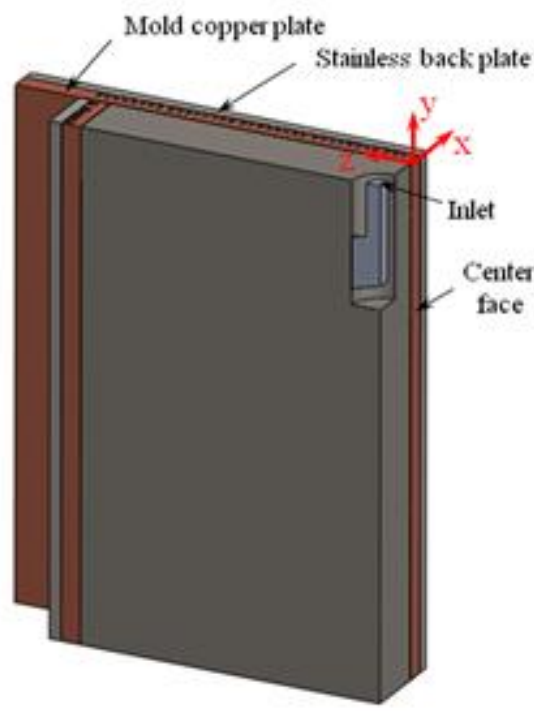

(a)

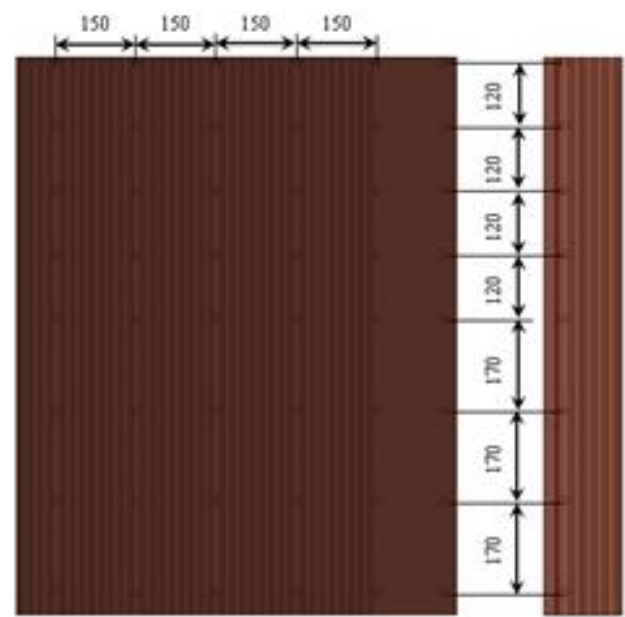

(b)

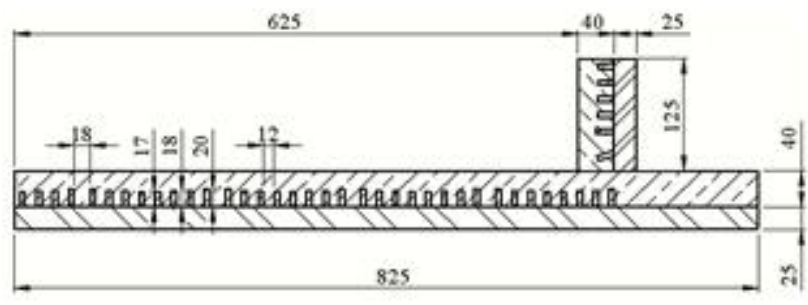

(c)

Fig. 1 Geometric shape of the model

(a) 1/4 model of Full SEN-3D FEMM, (b) position of fixing bolts, (c) mold section The geometric factors of the SEN used in computation are listed in Table 1. 


\begin{tabular}{c|c|c|c}
\hline Immersion depth, mm & $\begin{array}{c}\text { Exit inclination } \\
\text { angle, }\end{array}$ & Bottom shape & $\begin{array}{c}\text { Bore diameter, } \\
\mathrm{mm}\end{array}$ \\
\hline-300 & -15 & Convex shape & 60 \\
\hline
\end{tabular}

When establishing a model, Ni-Cr coating layer on the heat face of copper plate was made uniform with the thickness as $0.5 \mathrm{~mm}$ by using the Shell formation function of Fluent program to reduce the computing time.

\subsubsection{Element model}

The optimal water slot structure of the wide face mold was designed in the way of applying the heat face flux density on the copper plate calculated from computation on the full 3D 1/4 mold model combined with SEN to the heat face of the element model as a boundary condition. The length and width of the element model is chosen as the distance between 2 fixing bolts $(150 \mathrm{~mm}$ in width, $120 \mathrm{~mm}$ in height), in consideration of the distance between fixing bolts on the wide face mold. Fig. 2 shows the established element model.

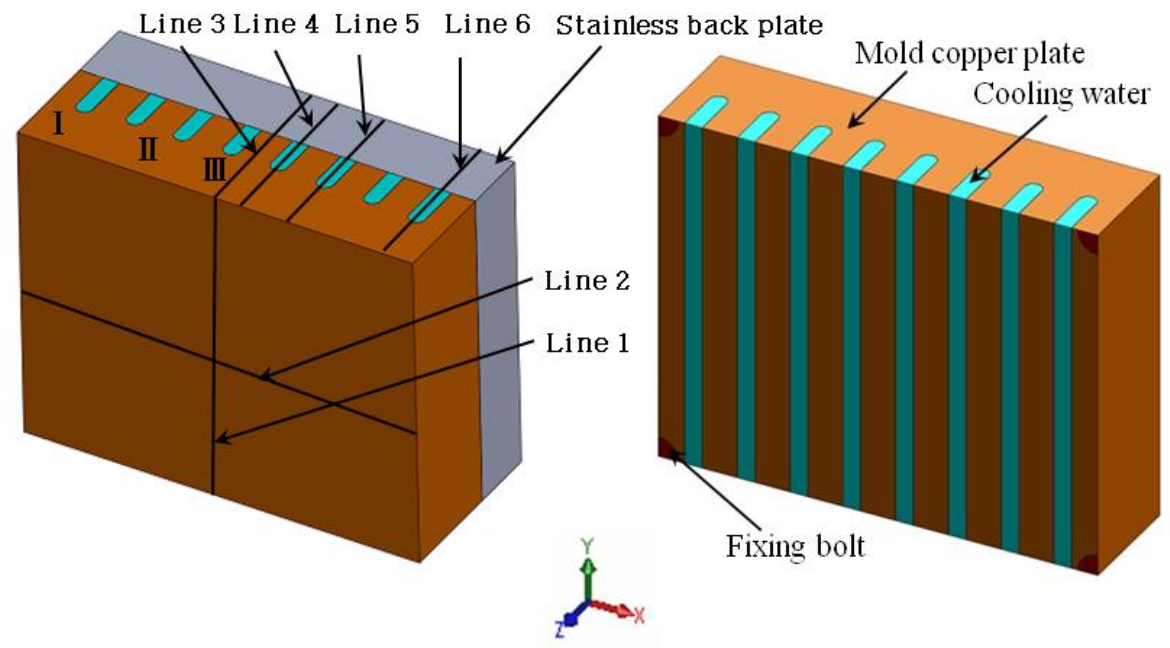

Fig. 2 Geometric shape of the element model

In the element model, the width of water slot is $6 \mathrm{~mm}$, the distance between water slots is $12 \mathrm{~mm}$ and the distance between water slots in the area that fixing bolt located is $18 \mathrm{~mm}$. In the element model, water slot is $6 \mathrm{~mm}$ in width, distance between water slots is $12 \mathrm{~mm}$ and distance between water slots in the area with fixing bolts is $18 \mathrm{~mm}$ in length. 4 methods for water slot design plan with different water slot depths are suggested to demonstrate the temperature distribution character of water slot depth on the heat face of element model. In the element model, the number 
of Slot I is 2, the number of Slot $I$ is 4 , and the number of Slot $I I$ is 2 .

4 different methods of water slot design plans are listed in Table 2.

Table 2 Slot depth for 4 different water slot design plans

\begin{tabular}{cccc} 
Characteristic index & I & & II \\
\hline Plan 1 & 19 & 18 & 18 \\
Plan 2 & 20 & 18 & 17 \\
Plan 3 & 21 & 18 & 16 \\
Plan 4 & 22 & 17 & 17 \\
\hline
\end{tabular}

The simulation results are obtained from the data on individual lines $1 \sim 6$, that are shown in Fig. 2.

\subsection{Mathematical model}

\subsubsection{Interface heat transfer model for temperature and flux field}

During the simulation of the temperature and flux field in the Full SEN-3D FEMM, the following assumptions are accepted:

First, the molten steel be incompressible fluid as contiguous medium, and the flux in steady state.

Second, the effects of mold oscillation and taper, solidification and shrinkage processes of the molten steel on the heat transfer through the mold and molten steel flux in the mold be ignored.

Third, the casting speed be constant and 3-dimensional heat transfer taken place in the mold.

Fourth, the Ni-Cr layer and mold flux film of solid phase may exist between the heat face on the copper plate and molten steel.

Fifth, the temperature of the cooling water along the vertical direction in the mold be distributed in linear.

Sixth, on the meniscus, covering slag layer be not considered, while heat insulation boundary condition be used.

Seventh, the taper of mold copper plate be ignored. 
(1) Mathematical model in fluid area

Continuity, momentum and standard k- equations used formulas in Ref [22] , and energy equation that in $\operatorname{Ref}[11]$.

(2) Mathematical model in solid area

Energy equations in mold copper plate and stainless back plate area used formulas in Ref [14].

(3) Mathematical model on the adjacent wall between solid and fluid

Heat flux on the near-wall

Heat transfer between cooling water and mold copper plate is expressed as the following expression

$$
q=h\left(T_{c}-T_{w}\right)
$$

Here

$$
\begin{aligned}
& \text { h-coefficient of heat transfer around the wall } \\
& \mathrm{T}_{\mathrm{c}} \text {-temperature of copper plate wall } \\
& \mathrm{T}_{\mathrm{w}} \text { - temperature of water near the copper plate wall }
\end{aligned}
$$

\section{Momentum equation}

The standard wall functions in ANSYS Fluent are based on the work of Launder and Spalding [20], and have been most widely used in industrial flows. The average velocity field in the standard wall functions is expressed by non-dimensional velocity $U^{*}$ as follows.

$$
U^{*}=\frac{1}{\kappa} \ln \left(E y^{*}\right)
$$

Here 
$\kappa$ - von Kármán constant (0.4187)

E-empirical coefficient $(9.793)$

$\mathrm{y}^{*}$-non-dimensional distance to the water slot wall surface

\section{Energy equation}

The coefficient of heat transfer in the flux boundary area during the heat transfer process between copper plate and cooling water is calculated according to the local heat transfer condition. It is presented as the following expressions, when considering the cooling water as incompressible fluid. In ANSYS Fluent, the temperature wall functions include the contribution from the viscous heating [21]. The law-of-the-wall implemented in ANSYS Fluent has the following composite form.

$$
\begin{aligned}
& T^{*}=\frac{\left(T_{c}-T_{w}\right) \rho C_{P} C_{\mu}^{1 / 4} k_{M}^{1 / 2}}{\&}=\left\{\begin{array}{l}
\operatorname{Pr} y^{*} \ldots \ldots \ldots \ldots \ldots \ldots \ldots \ldots\left(y^{*}<y_{T}^{*}\right) \\
\operatorname{Pr}_{t}\left[\frac{1}{\kappa} \ln \left(E y^{*}\right)+J\right] \ldots \ldots \ldots\left(y^{*}>y_{T}^{*}\right)
\end{array}\right. \\
& J=9.24\left[\left(\frac{\mathrm{Pr}}{\mathrm{Pr}_{t}}\right)^{3 / 4}-1\right]\left[1+0.28 e^{-0.007 \mathrm{Pr} / \mathrm{Pr}_{t}}\right]
\end{aligned}
$$

In these expressions $\mathrm{J}$ is calculated by using the formula suggested by Jayatilleke [21].

Here

$$
\begin{aligned}
& \text { \&-heat flux on the wall } \\
& \text { Pr- molecular Prandtl number }\left(\operatorname{Pr}=\mu C_{P} / k\right) \\
& \operatorname{Pr}_{t} \text { - turbulent Prandtl number }(0.85 \text { at the wall }) \\
& \rho \text {-density, } \mathrm{kg} / \mathrm{m}^{3} \\
& C_{p} \text {-specific heat, } J /(\mathrm{kg} \cdot \mathrm{K}) \\
& \mathrm{C}_{\mu} \text {-constant }
\end{aligned}
$$




$$
\begin{aligned}
& \mu_{\text {-coefficient of viscosity, } \mathrm{kg} /(\mathrm{m} \cdot \mathrm{s})} \\
& \lambda \text {-heat conductivity, } \mathrm{W} /(\mathrm{m} \cdot \mathrm{K})
\end{aligned}
$$

\subsubsection{Stress model}

During the simulation process on stress model, the followings are assumed.

First, all the materials be isotropic ones.

Second, the effect of Ni-Cr layer on the heat face on the mold copper plate be ignored.

Third, only elastic deformation may occur on the stainless back plate because of its comparatively low temperature, while elastic and plastic ones on the mold copper plate because of its comparatively high temperature

Fourth, the element model be symmetric on the $\mathrm{x}$ direction.

Fifth, initial stress by combination of bolts between mold copper plate and stainless back plate be ignored, and the copper plate be in facial contact with stainless back one on the fixing bolt position.

The total strain in the copper plate during continuous casting be expressed by the total sum of elastic, plastic and thermal strains in the calculation of the strain and stress.

$$
\varepsilon_{i j}=\varepsilon_{i j}^{e}+\varepsilon_{i j}^{p}+\varepsilon_{i j}^{T}
$$

Plasticity strain is simulated by considering the viscoplastic relationship of the isotropyhardening.

$$
\varepsilon_{i j}^{P}=\frac{3}{2} \frac{\varepsilon_{e}}{\Phi\left(\varepsilon_{e}\right)} S_{i j}
$$

Here

$$
\Phi\left(\varepsilon_{e}\right)=\sigma_{y}+\frac{E \cdot E}{E-E_{1}} \varepsilon_{e}
$$

Here 
$\mathrm{S}_{\mathrm{ij}-}$ deviatoric stress tensor

$\sigma_{\mathrm{y}}$ - yield stress

$\mathrm{E}$ and $\mathrm{E}_{1}$-Young`s modulus and linear hardening gradient

$\varepsilon_{\mathrm{e}^{-}}$Von-Mises equivalent strain

Thermal strain by the temperature change $\Delta \mathrm{T}$ is as follows.

$$
\varepsilon_{i j}^{T}=\alpha \Delta T \delta_{i j}
$$

Here

$\alpha$-the coefficient of thermal expansion

$\delta_{\mathrm{ij}-\text { Kronecker's delta }}$

\subsubsection{Process factors and thermo-physical properties of the materials}

The CC process factors used in the simulation are listed in Table 3.

Table 3 The CC process factors used in the simulation

\begin{tabular}{cc}
\hline Item & Value \\
\hline Casting speed, $\mathrm{m} / \mathrm{min}$ & 0.8 \\
Slab width, mm & 1250 \\
Slab thickness, mm & 250 \\
Mold height, mm & 1200 \\
Meniscus level(below mold top face), mm & 100 \\
wemperature difference between entry and exit of cooling & $7.2 / 7.4$ \\
Water flux(wide face/narrow face) ${ }^{\circ}{ }^{\circ} \mathrm{C}$ & \\
\hline
\end{tabular}

Physical properties of carbon steel described in Ref [23] are used in the simulation.

The thermo-physical properties of Ni-Cr layer and mold flux one on solid phase are listed in Table 4.

Table 4 Thermo-physical properties of Ni-Cr and mold flux layers

\begin{tabular}{cccc}
\hline Ni-Cr coating layer & Value & solid slag layer & Value \\
\hline Density, $\mathrm{kg} / \mathrm{m}^{3}$ & 7950 & Density, $\mathrm{kg} / \mathrm{m}^{3}$ & 2500 \\
Specific heat, $\mathrm{J} /\left(\mathrm{kg} \cdot{ }^{\circ} \mathrm{C}\right)$ & 615 & Specific heat, $\mathrm{J} /\left(\mathrm{kg} \cdot{ }^{\circ} \mathrm{C}\right)$ & 685 \\
Heat conductivity $\mathrm{W} /\left(\mathrm{m} \cdot{ }^{\circ} \mathrm{C}\right)$ & 20 & Heat conductivity $\mathrm{W} /\left(\mathrm{m} \cdot{ }^{\circ} \mathrm{C}\right)$ & 1.3 \\
\hline
\end{tabular}

Data reported in Ref [19] were used for the thermo-physical properties of $\mathrm{Cu}-0.65 \mathrm{Cr}-0.1 \mathrm{Zr}$ 
copper alloy in mold

Values in Workbench database were used as they were for the thermo-physical properties of austenite stainless steel.

\subsubsection{Boundary condition}

\subsubsection{Full model}

$0 \mathrm{~W} / \mathrm{m}^{2}$ is given to the heat flux densities on the top and bottom faces of mold copper plate, free surface of molten steel and the wall of SEN, and the temperature on the back face of the stainless steel back plate is chosen to be $50^{\circ} \mathrm{C}$.

The flux rate of cooling water in the passage on the cooling face of copper plate is chosen, in consideration of real production condition, to be $7.16 \mathrm{~m} / \mathrm{s}$, while the temperature difference between entry and exit of cooling water to be $7^{\circ} \mathrm{C}$.

The SEN passage rate of molten steel is, in consideration of casting rate, calculated and symmetry plane boundary condition is applied on all the symmetry planes.

\subsubsection{Element model}

The simulation order of temperature field, strain and stress ones in the element model is the same as follows (Fig. 3).

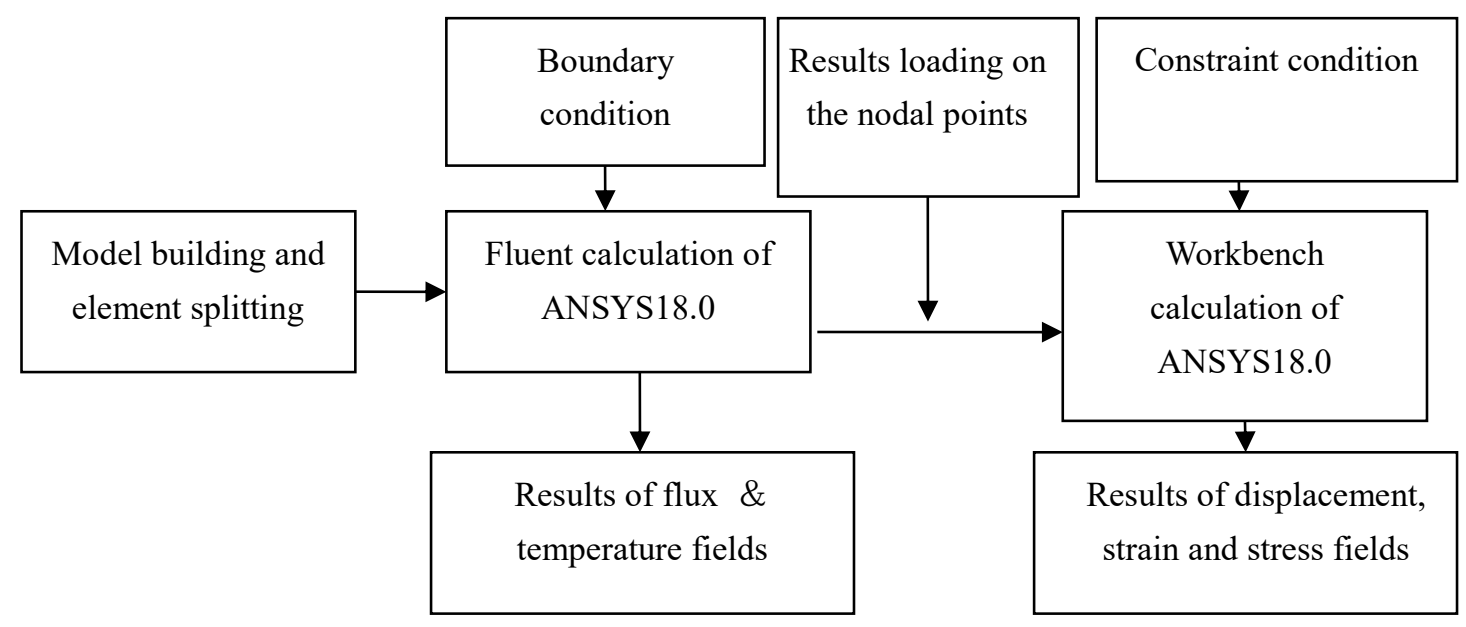

Fig. 3 Schematic diagram of simulation order of temperature field, strain and stress fields

The maximum heat flux density values derived from simulation results about the Full SEN- 
3D FEMM are used on the heat surface of the element models.

The bottom of element model is placed at the position with the maximum heat flux density value in mold copper plate, while its top at the position with the range of $120 \mathrm{~mm}$ upwards; hereby the user-defined function (UDF) is applied so as to make heat flux density changes on heat face just equal to those in the Full SEN-3D FEMM. The relational expression of the heat flux function on the heat face when using UDF is as follows.

$$
q=\mathrm{b}-\mathrm{a} y
$$

Here

a, b-constant

$y$ - coordinate along the height direction of element model, $\mathrm{m}$

The temperature difference of cooling water between entry and exit in the mold is set as $\triangle$

$\mathrm{T}=0.7^{\circ} \mathrm{C}$. The temperature of the back face of stainless back plate is as $50^{\circ} \mathrm{C}$, and the sides and top and bottom faces are treated by heat-insulated condition.

The constraint conditions for structural analysis were applied on the bolt face shown in Fig 2, the displacement values on the side face, top face and bottom face for the element model are set as $0 \mathrm{~mm}$ to consider the strain along the only $\mathrm{z}$ directional.

\section{Result and discussion}

3.1 Distribution character of flux field of molten steel and heat flux density on heat face for Full SEN3D FEMM

Element splitting on the Full SEN-3D FEMM built by Solidworks is done by using Gambit program to be called into ANSYS 18.0 Package program so as to simulate flux and temperature fields, and strain and stress ones by using Fluent program. The number of Meshed elements is 1 664 544, the number of Faces 3697863 , the number of Nodes 438449 and the number of for the Full SEN-3D FEMM. The distribution of flux line of molten steel and heat flux density on the wide and narrow heat faces in the mold for the Full SEN-3D FEMM is shown in Fig. 4. 


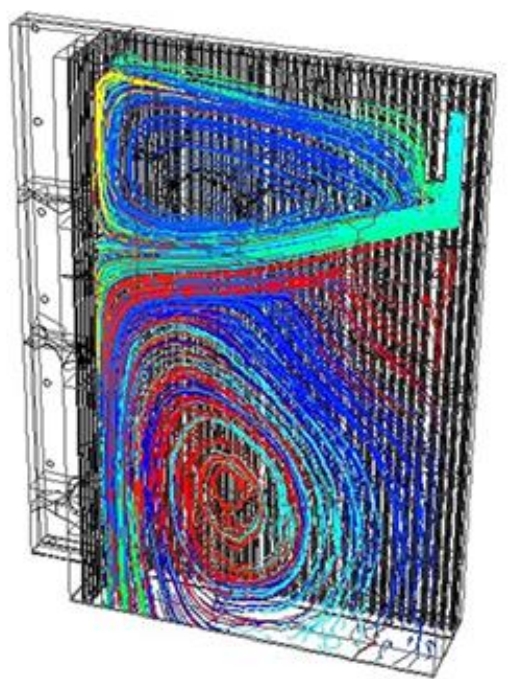

(a)

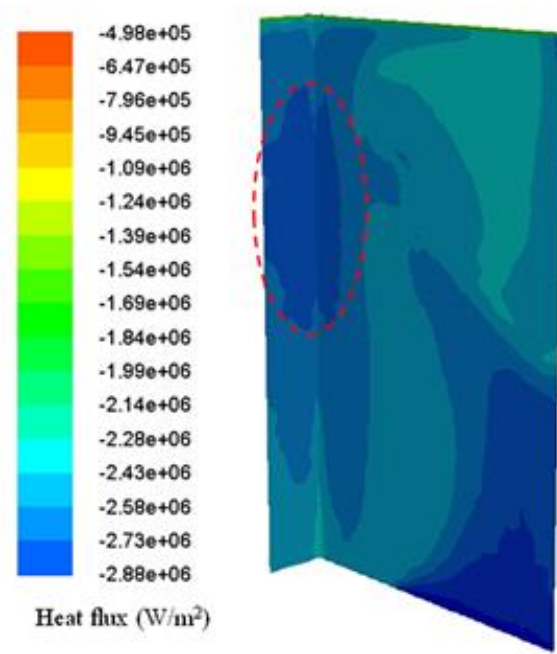

(b)

Fig. 4 The distribution of flux line pattern of molten steel and heat flux density on wide and narrow faces in the mold

a flux line, b heat flux density

As shown in the figure, the injected molten steel into the mold through SEN strikes the narrow face copper plate in the mold to form upward and downward turbulent flux. Especially, the maximum heat flux density is considered to be on the wide and narrow mold faces $370 \mathrm{~mm}$ away downwards from the top mold face. This is because the molten steel of higher temperature injected into the mold through the SEN strikes the narrow mold face to move to wide face in the mold as shown in Fig. 5b, and as the result, the temperature comparatively increases on the first contact area of the molten steel injected through the SEN with narrow mold copper plate face and on the second contact area of the wide mold copper plate face (Fig. 5a). 

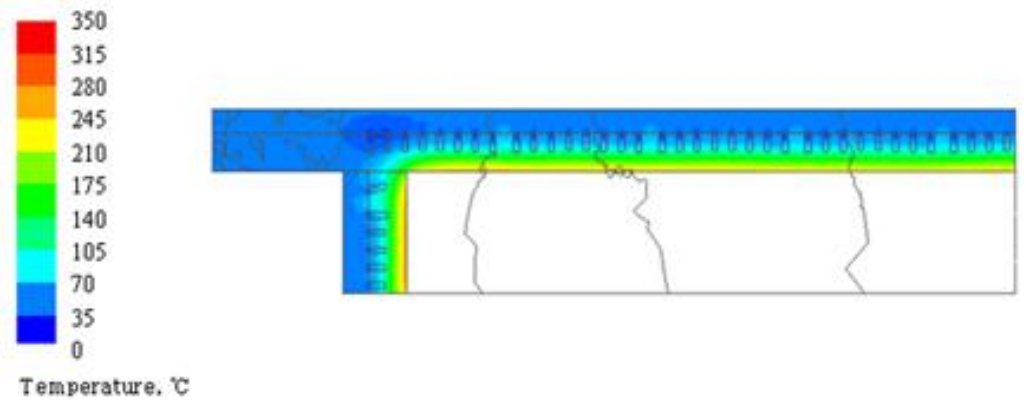

(a)
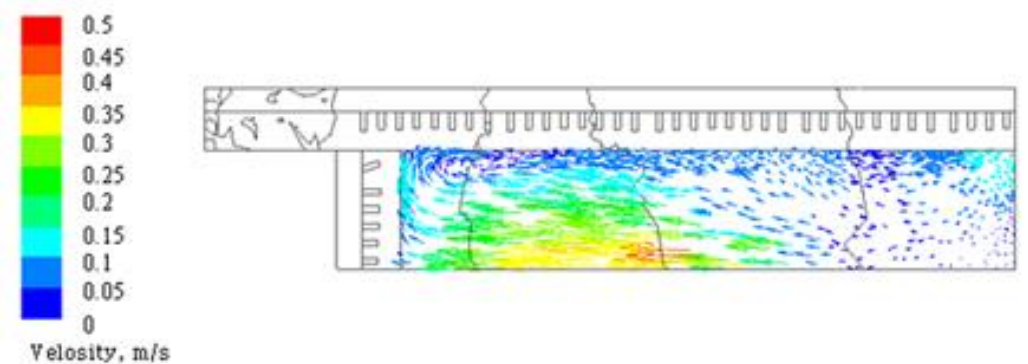

(b)

Fig. 5 Temperature and molten steel flux fields on the section $370 \mathrm{~mm}$ away from the meniscus. a Temperature field, $\mathbf{b}$ molten steel flux field

Fig. 6 shows the temperature and heat flux density distribution on the narrow and wide mold faces along the transverse direction at the position $370 \mathrm{~mm}$ away downwards from the meniscus. In the figure, approximate respectively is the changing tendency of heat flux density and temperature values on the wide and narrow faces of the mold. Especially, heat flux density and temperature have minimum values in the corner, and the farther away from the corner, the more rapidly they increase. Fig. 7 shows the distribution of heat flux density in the range area of $100 \sim 600 \mathrm{~mm}$ below the meniscus on the vertical line on the heat face of wide copper plate $15 \mathrm{~mm}$ away from the slab corner. 


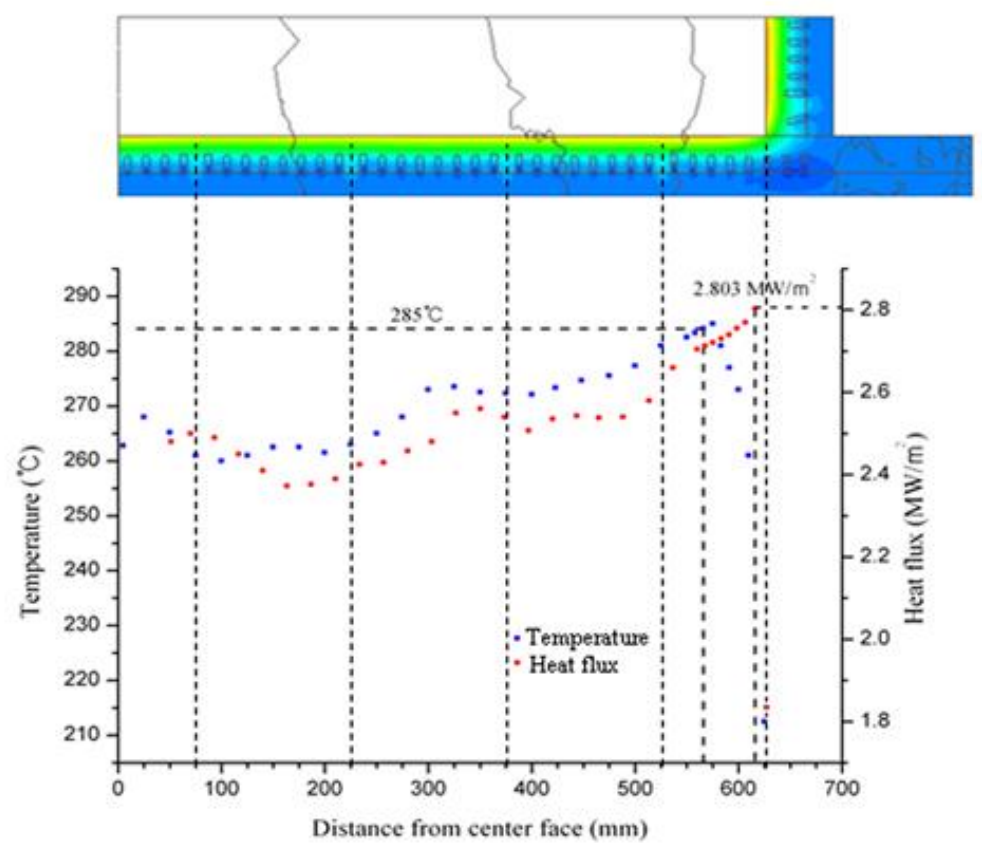

(a)

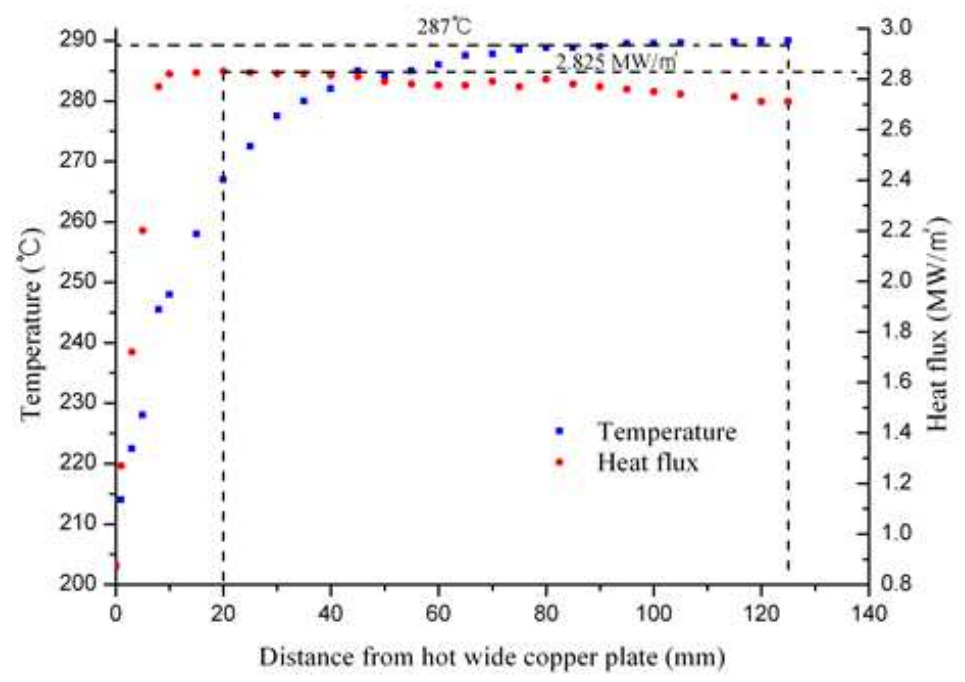

(b)

Fig. 6 The temperature and heat flux density distribution on the heat face at the position $370 \mathrm{~mm}$ away from the meniscus.

a wide face, $\mathbf{b}$ narrow face

As shown in the Fig. 7, when considering the distance between the fixing bolts is $120 \mathrm{~mm}$ with the maximum heat flux position of the wide copper plate face as standard, the heat flux density at the bottom is $2.803 \mathrm{MW} / \mathrm{m}^{2}$ while the heat flux density at the top is $2.7815 \mathrm{MW} / \mathrm{m}^{2}$. As the solidification and shrinkage process and mold taper are ignored for the Full SEN-3D FEMM, it can't be considered the formation of air allowance due to the constraint of the billet and mold flux membrane at the bottom part of the mold and the increase of the thermal resistance from it. As the 
solidification and shrinkage process and mold taper are ignored for the Full SEN-3D FEMM, so considered can't be the formation of air gap due to the shrinkage of the slab solidification shell and mold flux film below the maximum heat flux density area and the ensuing increase of the thermal resistance. Thus, it is considered to be important to determine the temperature and stress field occurring on the heat face of mold copper plate in the maximum heat flux density area by applying as it is the maximum heat flux density on the heat face of the mold copper plate obtained in the simulation of Full SEN-3D FEMM with considering the heat resistance layers including mold flux and mold copper plate ones to the element model without considering them to save the counting time.

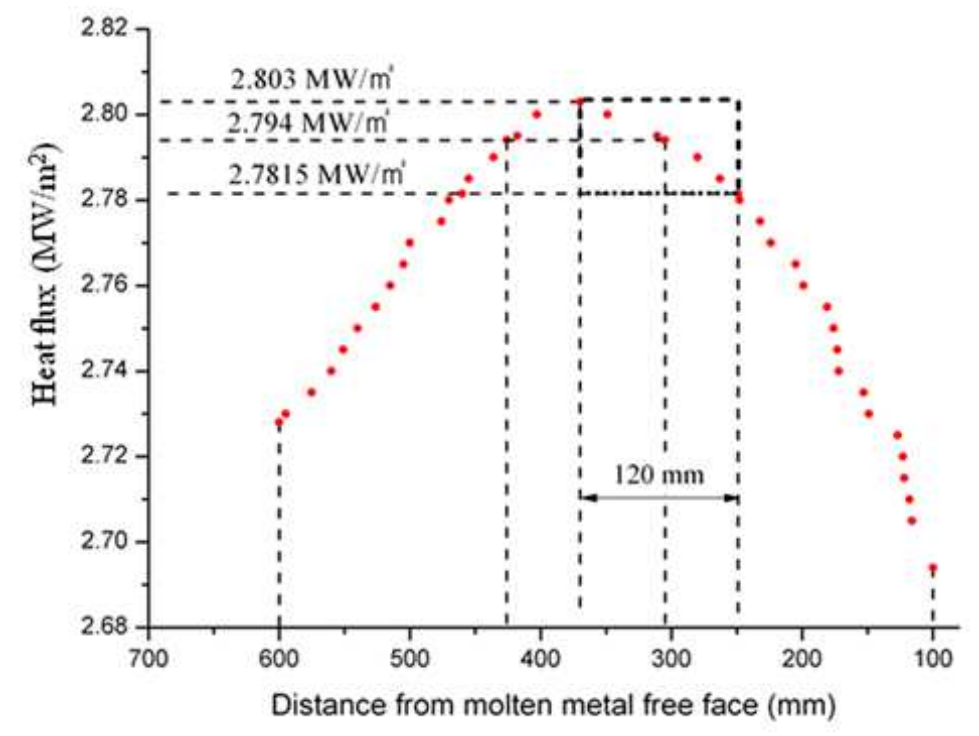

Fig. 7 The distribution of heat flux density in the range area of $100 \sim 600 \mathrm{~mm}$ below the meniscus on the vertical line on the heat face of wide copper plate $15 \mathrm{~mm}$ away from the slab corner

\subsection{Temperature field distribution character on the heat face of the element model}

The temperature distribution on the copper plate heat face is regarded as a factor that has a great influence to the thermal stress and strain on the copper plate heat face. When the temperature distribution on the copper plate heat face is non-uniform, the temperature increase in the individual heat face nodes brings different thermal stains to generate heat stress, thus giving a great influence to the lifetime of the copper plate. The copper plate thickness, cooling water flux rate and cooling water slot depth are selected as the factors that affect the temperature distribution character on the 
heat face of the element model and considered were the effects of individual factors on the temperature distribution on the copper plate heat face.

\subsubsection{Temperature field distribution character on the heat face of copper plate along with the plate thickness change.}

The temperature field simulation in a certain element model corresponding to Plan 2 is proceeded with changing the thickness of the copper plate in the range of $35 \sim 50 \mathrm{~mm}$ to determine the effect of the copper plate thickness on the temperature field distribution on the copper plate heat face. The maximum and minimum temperatures on the copper plate heat face are gained from the temperature field contour curves on the heat face. The variations of maximum temperature $\left(T_{\max }\right)$ and minimum temperature $\left(\mathrm{T}_{\min }\right)$ and the difference value $(\Delta \mathrm{T})$ between them on the hace of the mold copper plate obtained from the simulation results are shown in the Fig 8.

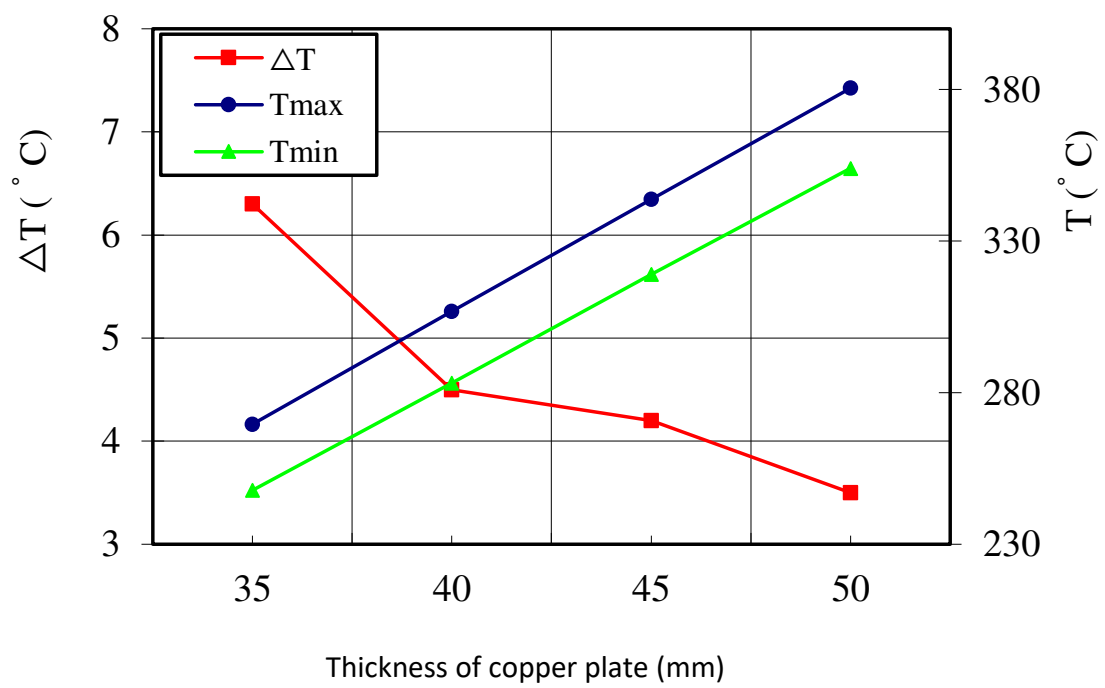

Fig. 8 The variations of $T_{\max }, T_{\min }$ and $\Delta T$ on the heat face according to the copper plate thickness

As shown in the figure, with the increase of copper plate thickness, the maximum and minimum temperatures on the heat face of the mold copper plate increases linearly while the difference between them decreases gradually. Especially, when the copper plate thickness is $\delta$ $=35 \mathrm{~mm}$ in minimum, the maximum temperature is $269.6^{\circ} \mathrm{C}$ and the minimum one is comparatively low with $263.3^{\circ} \mathrm{C}$ on the heat face, whereas the difference between the maximum 
and minimum temperature is comparatively high with $6.3^{\circ} \mathrm{C}$; but when the thickness of copper plate is $\delta=50 \mathrm{~mm}$ in the maximum, the maximum temperature is $380.4^{\circ} \mathrm{C}$ and the minimum temperature is comparatively high with $376.9^{\circ} \mathrm{C}$ on the heat face, and the difference between the maximum and minimum temperature is comparatively low with $3.5^{\circ} \mathrm{C}$. So it can be seen that with the increasing the thickness of the copper plate, the temperature on the heat face becomes more uniform but the temperature on the heat face increases. When the thickness of the copper plate increases $15 \mathrm{~mm}$ from $\delta=35 \mathrm{~mm}$ to $\delta=50 \mathrm{~mm}$, the maximum temperature on the heat face increases as high as about $104.6^{\circ} \mathrm{C}$ and the minimum temperature also increases as high as about $106.2^{\circ} \mathrm{C}$. This indicates the thickness of the copper plate is the most important factor that affects the temperature field of the mold copper plate.

\subsubsection{Temperature field distribution character on the copper plate heat face according to the cooling water slot depth}

The cooling water slot has a great influence on the temperature field distribution on the copper plate heat face as the depth of the water slot facing the heat face side of the mold copper plate. To demonstrate the effect of the cooling water slot depth on the temperature field distribution on the heat face of the mold copper plate, 4 plans on element models with different cooling water depths on the mold copper plate of $40 \mathrm{~mm}$ in thickness under the condition of other uniform process factors. The temperature distribution on the heat face midline $(\mathrm{y}=60 \mathrm{~mm})$ of the element model for 4 plans obtained from the simulation results is shown in the Fig 9. 


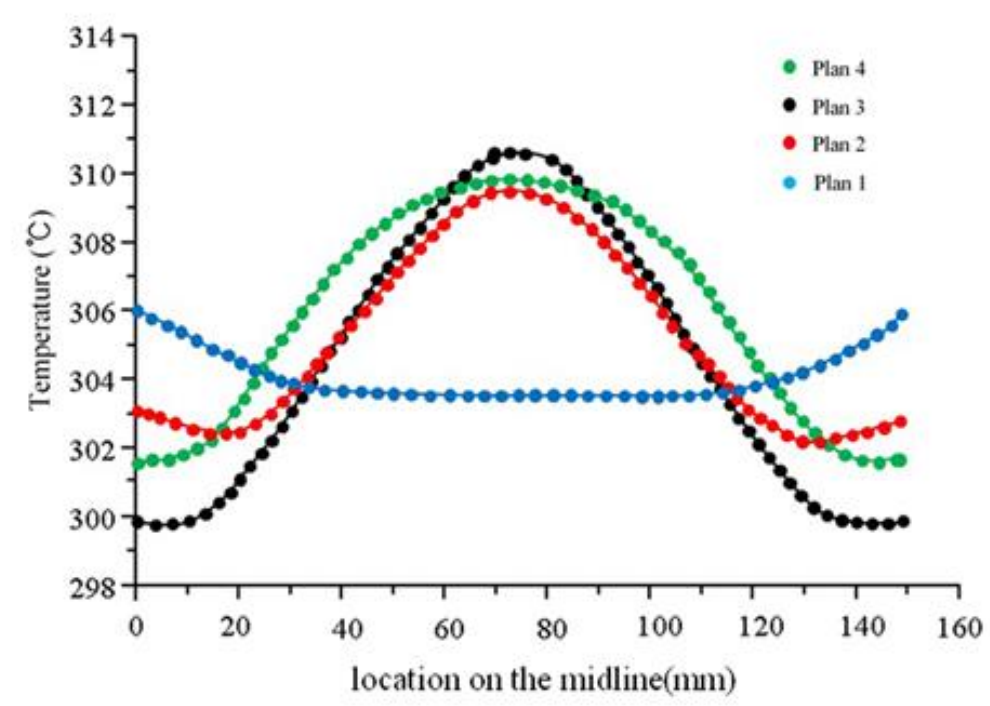

Fig. 9 The temperature field on the heat face of mold copper plate in 4 plans

As shown in the figure, when using Plan 1, the depth of cooling water slot I is comparatively shallow while the depths of cooling water slots II and III are comparatively deep with the same in depth and, thus resulting the temperature distribution curve on the mold heat face distributed in concave type. This means that the temperature in the area between 2 neighbored cooling water slot Is, i.e. in fixing-bolt area increases. But as shown in the simulation results, the temperature distribution curve on the heat face of the mold copper plate is in convex shape in Plans 2, 3 and 4. The maximum $\left(\mathrm{T}_{\max }\right)$ and minimum $\left(\mathrm{T}_{\min }\right)$ temperatures on the heat face of mold copper plate and the difference $(\triangle T)$ between them based on the simulation result are shown in Fig. 10.

As shown in the figure, it is just in Plan 2 that the maximum and minimum temperature on the heat face on the mold copper plate is the lowest and the inter-difference between them is the smallest. Fig. 11 shows the temperature distribution on the lines 3, 4, 5 and 6 on the mold copper plate in Plan 2 when the cooling water flowing rate is $7.16 \mathrm{~m} / \mathrm{s}$. At this time, individual lines are put on the plane with $y=-110 \mathrm{~mm}$ of the maximum. As shown in the figure, considering the temperature distribution character from heat face of mold copper plate to back of stainless steel bracing plate, it increase linear from the heat face to water slot edge face and suddenly decreases in the water slot area $(0 \sim 17 \mathrm{~mm})$. As shown in the figure, considering the temperature distribution state from heat face of mold copper plate to the back face of stainless back plate, it decreases nearly linearly from the heat face to water slot edge face but suddenly does in the water slot 
$\operatorname{area}(0 \sim 17 \mathrm{~mm})$.

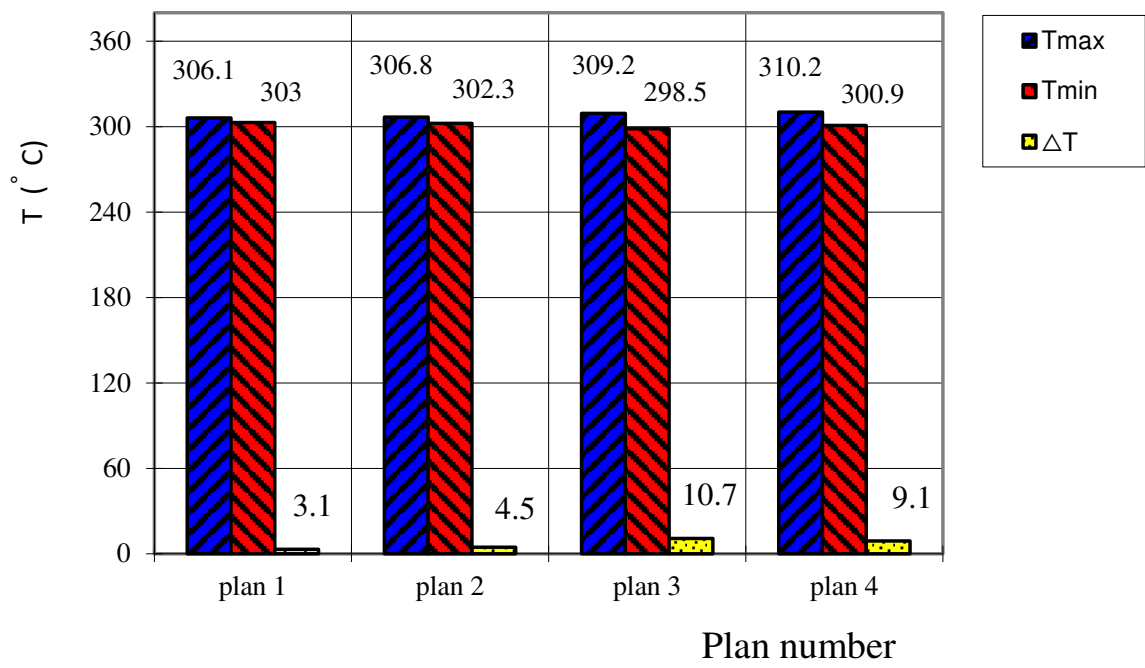

Fig. 10 The variations of $T_{\max }, T_{\min }$ and $\Delta \mathrm{T}$ on the heat face according to plan number

In the given process parameter condition, the $\mathrm{ABCD}$ area in the figure is the inner area of the water slot where the temperature is higher than $100^{\circ} \mathrm{C}$, which is located on the heat face side and the maximum temperature in this area is $137.5^{\circ} \mathrm{C}$. Under the given process factor condition, as the $\mathrm{ABCD}$ area in the figure is the internal one of the water slots with the temperature above $100^{\circ} \mathrm{C}$, the maximum temperature in this area reaches $137.5^{\circ} \mathrm{C}$. As the boiling point of water is $168.501^{\circ} \mathrm{C}$ when the cooling water pressure is $0.7 \mathrm{MPa}$ derived from the pressure-boiling point relational formula(1) in Ref [6], thus it can be seen that the boiling phenomenon doesn`t present in the ABCD areas. 


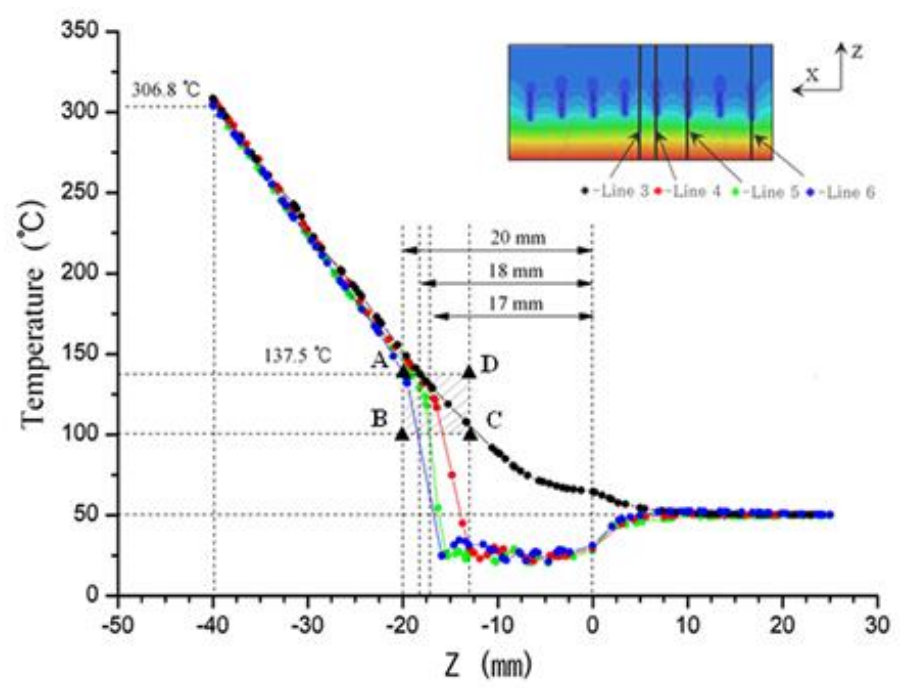

Fig. 11 The temperature distribution on the lines $3 \sim 6$.

\subsection{Deformation and stress distribution in the element model}

The mold copper plate has the effect of elastic and plastic strain due to the temperature gradient on the section during working process; so once plastically strained, it remains as the permanent deformation state after working to strain-harden the mold copper alloy. If such permanent deformation accumulates, the heat face shape deforms to affect the solidification shell type of slab and furthermore, tends to cause an accident of slab or copper plate crack. Generally, thermal strain mainly depends on temperature gradient and the thermal expansion coefficient in the mold copper alloy [4]. Strain and stress field simulation on the element model is proceeded according to the strain and stress field simulation orders shown in Fig. 3. Applying Fluent \& Workbench programs of ANSYS 18.0 Package to the same geometrical objects, the temperature values on each node in solid determined from Fluent simulation are loaded as initial ones thermal and structural analysis model to proceed the analysis. Fig. 12 shows the simulation result in the element model in Plan 2.

\subsubsection{Changing character of total deformation and thermal strain according to thickness of copper plate}

Fig. 13 shows total deformation and thermal strain occurring on the copper plate of element model assembled with stainless back plate. At this time, Plan 2 is chosen as the water slot plan and the cooling water flux rate is $7.16 \mathrm{~m} / \mathrm{s}$. As shown in the figure, the more the copper plate increases, the more nearly linearly the total deformation and thermal strain on the copper plate increases. 
Especially when the thickness of copper plate increases from $35 \mathrm{~mm}$ to $50 \mathrm{~mm}$, the total deformation does from $0.168,69 \mathrm{~mm}$ to $0.386,32 \mathrm{~mm}$ by 2.153 times and the thermal strain increases from $4.2341 \mathrm{~mm} / \mathrm{m}$ to $6.4722 \mathrm{~mm} / \mathrm{m}$ by 1.53 times. The $\mathrm{x}$ and $\mathrm{y}$ directional displacements are assumed as 0 during the simulation, thus indicating the total deformation obtained from the simulation as the $\mathrm{z}$ directional deformation. Considering the simulation results of Fig. 12, the maximum deformation and thermal strain all appeared on the heat face of copper plate with the highest temperature, which shows the maximum deformation and thermal strain are all the functions of temperature. In the fluent simulation results, the temperature increases from cross section to heat face of the copper plate and the total deformation and thermal strain increase in proposition to this temperature increase.
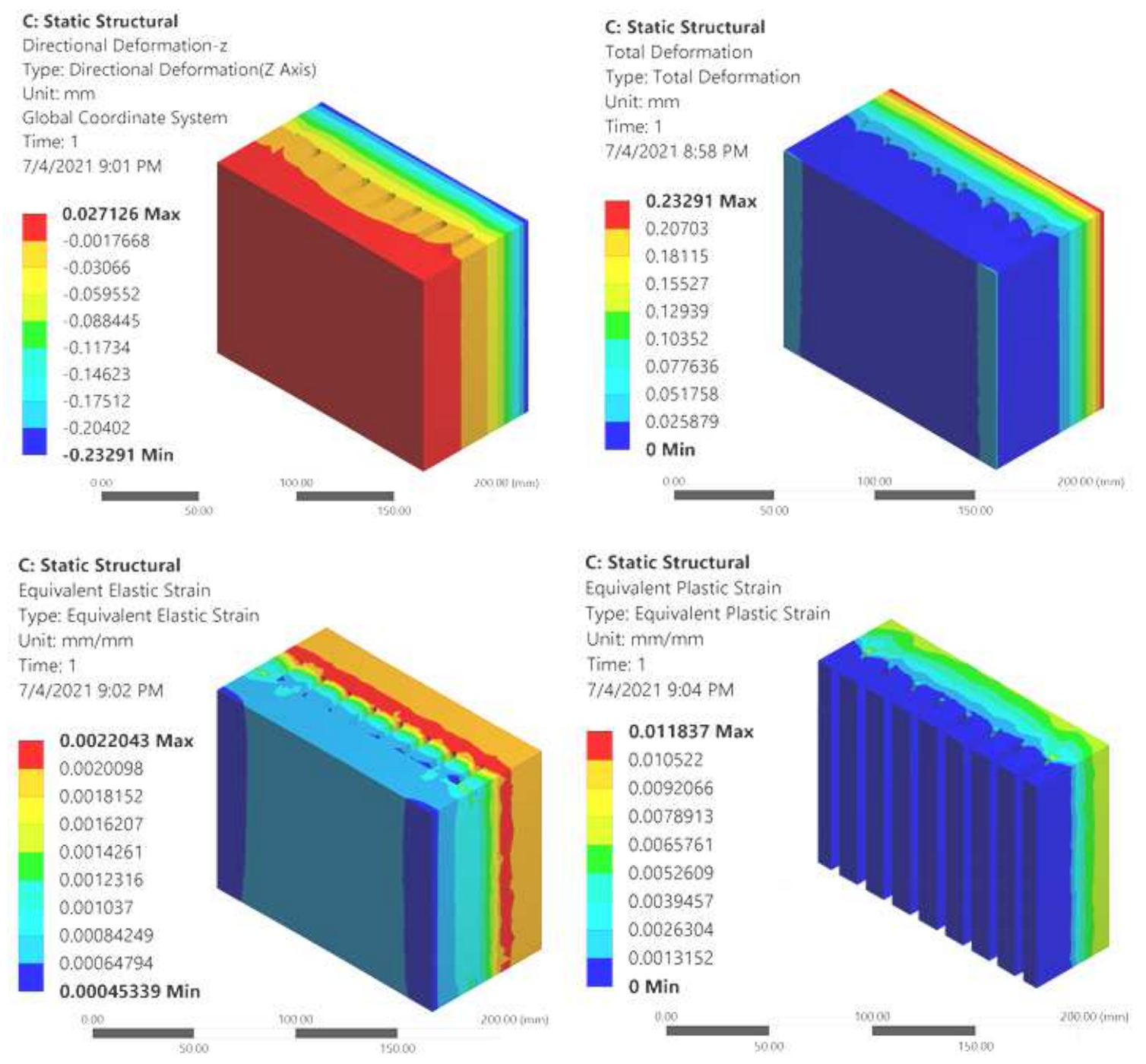

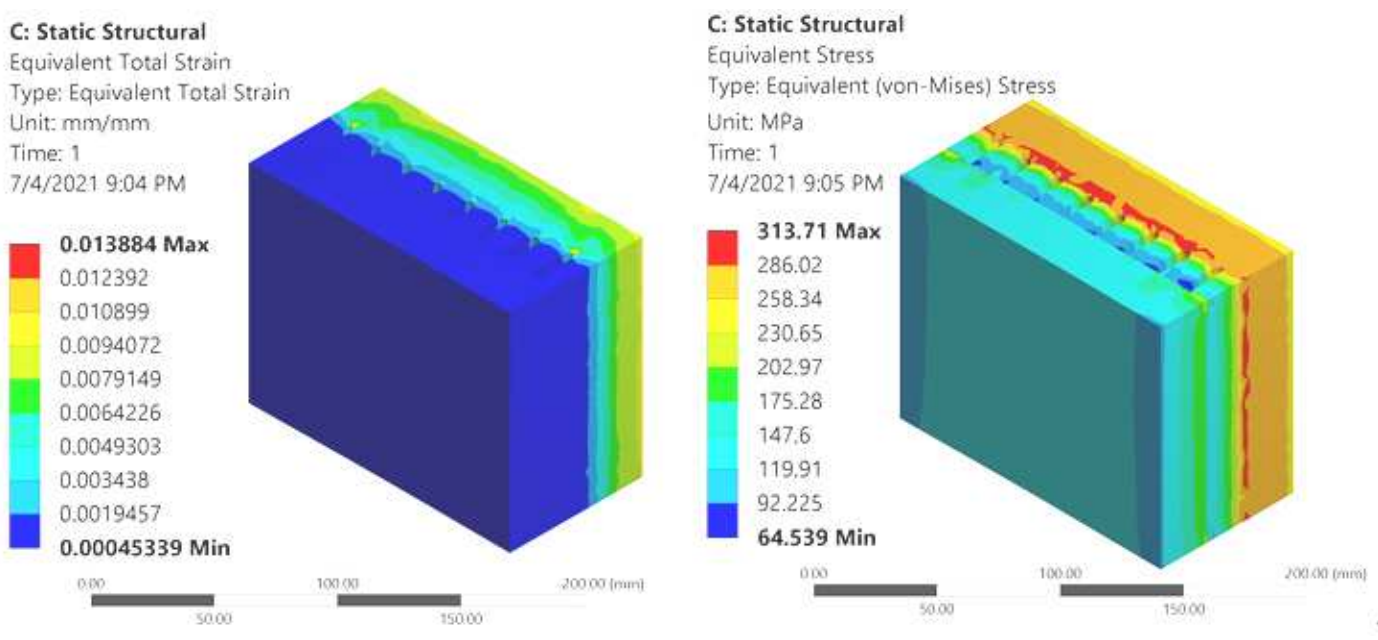

Fig. 12 Simulation results on plan 2

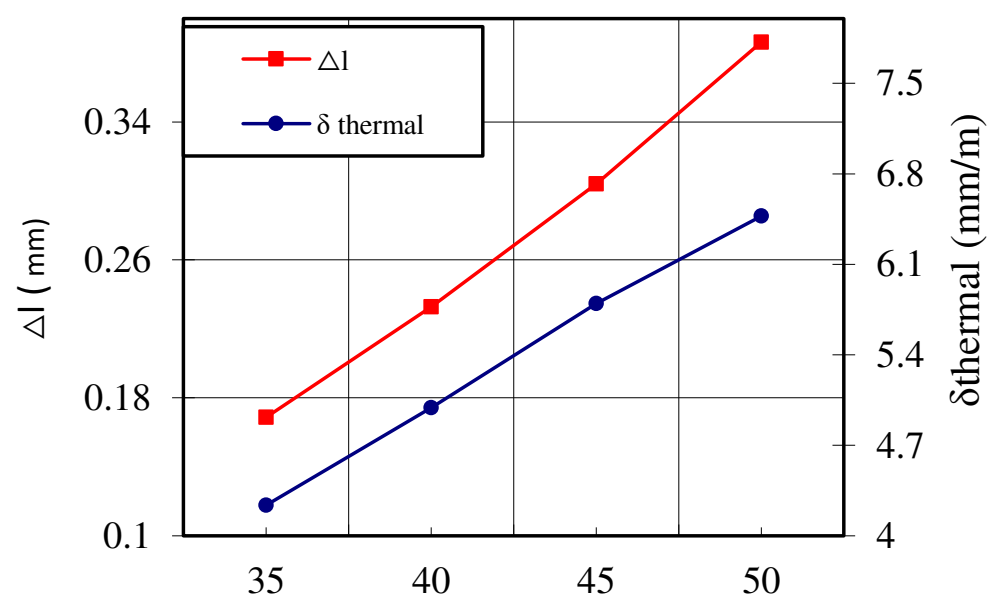

Thickness of copper plate (mm)

Fig. 13 Total deformation and thermal strain change according to the thickness of copper

$$
\text { plate }
$$

\subsubsection{Changing character of total deformation and thermal strain according to depth of cooling water} slot.

Table 5 shows total deformation and thermal strain along the slot depth of cooling water occurring on the copper plate of element model assembled with stainless back plate. At this time, Plan 2 is used for the water slot plan and the copper plate is $40 \mathrm{~mm}$ in thickness. 
Table 5 Total deformation and thermal strain changes according to the slot depth of cooling water.

\begin{tabular}{ccccc}
\hline Plan number & Plan 1 & Plan 2 & Plan 3 & Plan 4 \\
\hline$\triangle l, \mathrm{~mm}$ & 0.2507 & 0.23291 & 0.2362 & 0.24463 \\
$\delta_{\text {thermal }, \mathrm{mm} / \mathrm{m}}$ & 5.2638 & 4.9915 & 5.0661 & 5.0745 \\
\hline
\end{tabular}

As shown in the table, different cooling water slot plans have different total deformation and thermal strain changes on the copper plate. Especially, the total deformation is $0.23291 \mathrm{~mm}$ and thermal strain is $4.9915 \mathrm{~mm} / \mathrm{min}$ when using Plan 2. As shown in Fig 12, total deformation and plastic strain concentratively appear towards $z$ direction around the heat face of element model and the maximum values of elastic strain and equivalent stress mainly appear around the water slot bottom area. And the maximum strain occurs in the water slots of maximum length placed around the fixing bolts, while all the water slots incline to both sides with the central vertical section as symmetrical face to be deformed. Because the displacement value at the 4 corners with fixing bolts in the element model is zero, with concentrated stress, the heat face on copper plate in the element model is deformed with the central part swollen.

This is the result of the placement of fixing bolts at 4 corners in the element model and comparatively high temperature in the central area. From the simulation results, it can be seen that the stress formed in the comparatively low temperature area lies in the elastic stress limit, so that elastic deformation may mainly occur around the water slot bottom; while plastic deformation mainly occurs around the heat face where the stress formed in the comparatively high temperature area exceeds the elastic stress limit.

\section{Conclusion}

The conclusion obtained from simulations on temperature field in the Full SEN-3D FEMM and on temperature, deformation and stress fields on the element model in the maximum heat flux density area is as follows.

(1) When the molten steel is injected through the SEN, it strikes the narrow mold face first and then changes its direction to strike the wide mold face.

Hence, the maximum heat flux density value is given around corner areas where narrow and wide faces contact with each other, and the maximum heat flux density on narrow face, the first contact one, is $2.825 \mathrm{MW} / \mathrm{m}^{2}$ and $2.803 \mathrm{MW} / \mathrm{m}^{2}$ on the wide face, the second contact one, in 
consideration of the mold flux film and coating layer.

(2) The maximum temperature on the heat face increases by about $37^{\circ} \mathrm{C}$ with the thickness of mold copper plate increasing by $5 \mathrm{~mm}$.

(3) In case of different water slot structures, the temperature distribution in horizontal direction changes on the heat face of mold copper plate, which nearly coincides with water slot depth distribution on the mold copper plate section.

When using Plan 19-18-18, the temperature distribution in horizontal direction is in concave shape and in convex shape for Plans 20-18-17, 21-18-16, 22-17-17.

(4) The minimum temperature on the heat face is given in the bottom of element model when heat flux density linearly decreases with the direction upward on the heat face of element model.

(5) In Plan 20-18-17, the maximum displacement in $\mathrm{z}$ direction increases by about $0.07 \mathrm{~mm}$ and thermal strain by about $0.8 \mathrm{~mm} / \mathrm{m}$ with the thickness of mold copper plate increasing by $5 \mathrm{~mm}$.

(6) During CC process, the equivalent elastic deformation due to the thermal stress is mainly concentrated around water slots, equivalent plastic deformation mainly appears around the heat face area of mold copper plate and the maximum equivalent plastic deformation appears on the bottom of water slots around fixing bolts.

\section{Acknowledgment}

The authors would like to express their gratitude to the editors, the authors of the references and the reviewers for their helpful suggestions for improvement and publication of this paper. 


\section{Declaration}

\section{Authors' contributions}

Sang Chol Om presented the idea about building of full 3D finite element mold model combined with submerged entry nozzle(SEN)(Full SEN-3D FEMM), differently with applying the heat flux density obtained by empirical formula reported in previous literatures to hot face of copper plate as constant, and obtained the optimum plan about the cooling water slot structure of mold copper plate, synthesizing the simulation results from the each simulation steps.

Dong Gil Kim determined the process parameters for continuous casting and the properties of each materials used for the above mentioned Full SEN-3D FEMM, suggested the heat resistance model including the coating and mold flux layer between the molten steel and the mold copper plate.

Chong Il Pak determined the structure, the dimension and the submerged depth of submerged entry nozzle(SEN) applied for Full SEN-3D FEMM.

Hak Yong Kim simulated the flow and temperature fields about Full SEN-3D FEMM using Fluent Program in ANSYS Package to get the data about the maximum heat flux density and temperature field on the heat face of mold copper plate.

Il Un Kim simulated the thermal stress and strain fields in the element model using Workbench Program in ANSYS Package applying the maximum heat flux density in the results obtained from the simulation about Full SEN-3D FEMM to the heat face on copper plate in the element one.

\section{Ethics declarations}

The authors approve to observe the ethics standard of this journal.

\section{Conflict of interest}

The authors declare that they have no conflict of interest.

\section{Open Access}

No open access. 


\section{Funding}

This research work was not funded.

\section{Availability of data and materials}

The authors confirm that the data supporting the findings of this study are available within this article.

\section{Availability of code}

The code that support the findings of this study are available from the corresponding author [Sang Chol Om], upon a reasonable request.

\section{References}

1. Wang TM, Cai SW, Xu J, Du YY, Zhu J, Xu JJ, Li TJ(2010) Continuous casting mould for square steel billet optimised by solidification shrinkage simulation. Ironmaking and Steelmaking 37(5):341 $\square 346$

2. Pandey JC, Raj Manish, Mishra Rajesh, Tripathy VK, Bandyopadhyay N(2008) Failure of Nickel Coating on a Copper Mold of a Slab Caster. J Fail. Anal. and Preven. 8: 3-11

3. Long Mujun, Chen Huabiao, Chen Dengfu, Yu Sheng, Liang Bin, Duan Huamei(2018) A Combined Hybrid 3-D/2-D Model for Flow and Solidification Prediction during Slab Continuous Casting. Metals 8: 182-191

4. Liu Xudong, Zhu Miaoyong(2006) Finite Element Analysis of Thermal and Mechanical Character in a Slab Continuous Casting Mold. ISIJ International 46(11): 1652-1659

5. Meng Xiangning, Zhu Miaoyong(2009) Thermal Character of Hot Copper Plates for Slab Continuous Casting Mold with High Casting Speed. ISIJ International 49(9): 1356-1361

6. Xin Xie, Chen Dengfu, Long Haijun, Long Mujun, Kui Lv (2014) Mathematical Modeling of Heat Transfer in Mold Copper Coupled with Cooling Water During the Slab Continuous Casting Process. METALLURGICALAND MATERIALS TRANSACTIONS 45(12): 24422452

7. Wang Xudong, Tang Ling, Zang Xinyang, Yao Man(2012) Mold transient heat transfer character based on measurement and inverse analysis of slab continuous casting. Journal of Materials Processing Technology 212: 1811-1818

8 Ren Feifei , Zhang Hui , Wang Weining, Wang Minglin(2015) Numerical simulation of actual 
temperature field for chamfered mold copper. Iron and Steel 50(4): 27-33

9. Badri A, Natarajan TT, Snyder CC, Powers KD, Mannion FJ, Cramb AW(2005) A Mold Simulator for the Continuous Casting of Steel: Part I. The Development of a Simulator. Metallurgical and Materials Transactions B 36B(6): 355-371

10. Dua Fengming, Wang Xudong, Yao Man, Zhang Xiaobing(2014) Analysis of the non-uniform thermal character in slab continuous casting mold based on the inverse finite-element model. Journal of Materials Processing Technology 214: 2676-2683

11. Cai Zhaozhen, Zhu Miaoyong(2013) Thermo-mechanical Character of Peritectic Steel Solidifying in Slab Continuous Casting Mold and A New Mold Taper Design. ISIJ International 53(10): 1818-1827

12. Niu Zhenyu, Cai Zhaozhen, Zhu Miaoyong(2019) Dynamic Distributions of Mold Flux and Air Gap in Slab Continuous Casting Mold. ISIJ International 59(2): 283-292

13. David T Stone, Brian G. Thomas(1999) MEASUREMENT AND MODELING OF HEAT TRANSFER ACROSS INTERFACIAL MOLD FLUX LAYERS. Canadian Metallurgical Quarterly 38(5): 363-375

14. Wang Xudong, Kong Lingwei, Du Fengming, Yao Man, Zhang XiaobingNG, Ma Han, Wang Zhe(2016) Mathematical Modeling of Thermal Resistances of Mold Flux and Air Gap in Continuous Casting Mold Based on an Inverse Problem. ISIJ International 56(5): 803-811 Doi: http://dx.doi.org/10.2355/isijinternational.ISIJINT-2015-601

15. Éldarkhanov AS, Nuradinov AS, Uzdieva NS, Nuradinov IA(2019) OPTIMIZATION OF THERMAL PERFORMANCE OF CCM MOLD. Metallurgist 63(1-2): 11-20

16. Meng Xiangning, Zhu Miaoyong(2013) Effect of cooling structure on thermal character of copper plates of slab continuous casting mold. J . Cent . South Univ . 20： 318-325

17. Zhou J, Peng X, Qin Y(2009) A coupled thermal-mechanical analysis of a mold-billet system during continuous casting. Int J Adv Manuf Technol 42: 421-428

18 Duan Mingnan, Feng Changbao, Yang Jianhua, Yuan Wei, Yang Ke(2008) Thermal and Mechanical Couple Stress Analysis of Mould Copper for Slab Continuous Casting. Iron and Steel 43(5): 30-34(in Chinese)

19. Luo W, Yan B, Lu X, Wen GH(2013) Improvement of water slot design for beam blank casting 
mould. Ironmaking and Steelmaking 40(8): 582-589

20. Launder BE, Spalding DB(1974) The Numerical Computation of Turbulent Flows. Computer Methods in Applied Mechanics and Engineering. 3: 269-289

21. Jayatillaka C(1969) The Influence of Prandtl Number and Surface Roughness on the Resistance of the Laminar Sublayer to Momentum and Heat Transfer. Prog. Heat Mass Transfer 1: 193-321

22. Tao Zhang, Jian Yang, Peng Jiang(2019) Measurement of Molten Steel Velocity near the Surface and Modeling for Transient Fluid Flow in the Continuous Casting Mold. Metals 9: $36-50$

23. Cai Zhaozhen, Zhu Miao-yong(2014) Non-uniform heat transfer character during shell solidification in a wide and thick slab continuous casting mold. International Journal of Minerals, Metallurgy and Materials 121(3): 240-250 


\section{Supplementary Files}

This is a list of supplementary files associated with this preprint. Click to download.

- Figures.rar 